\title{
Adverse Selection in Private Annuity Markets and the Role of Mandatory Social Annuitization
}

\author{
Ben J. Heijdra • Laurie S. M. Reijnders
}

Published online: 28 April 2012

(C) The Author(s) 2012. This article is published with open access at Springerlink.com

\begin{abstract}
We study the effects on the macroeconomic equilibrium, the wealth distribution, and welfare of adverse selection in private annuity markets in a closed economy inhabited by overlapping generations of heterogeneous agents who are distinguished by their health status. If an agent's health type is private information there will be a pooling equilibrium in the private annuity market. We also study the implications for the macro-economy and welfare of a social security system with mandatory contributions that are constant across health types. These social annuities are immune to adverse selection and therefore offer a higher rate of return than private annuities do. However, they have a negative effect on the steady-state capital intensity and welfare. The positive effect of a fair pooled rate of return on a fixed part of savings and a higher return on capital in equilibrium is outweighed by the negative consequences of increased adverse selection in the private annuity market and a lower wage rate.
\end{abstract}

A previous version of this paper formed part of the second author's bachelor thesis which was awarded the 2011 Netspar Bachelor Thesis Award. It was also joint winner of the 2011 Grote Financiën Scriptieprijs, a thesis prize established by the Dutch Ministry of Finance.

B. J. Heijdra $(\varangle)$. L. S. M. Reijnders

Faculty of Economics and Business, University of Groningen, P. O. Box 800, 9700 AV

Groningen, The Netherlands

e-mail: b.j.heijdra@rug.nl

B. J. Heijdra

IHS, Vienna, Austria

B. J. Heijdra

CESifo, Munich, Germany

B. J. Heijdra · L. S. M. Reijnders

Netspar, Tilburg, The Netherlands

e-mail: 1.s.m.reijnders@ rug.nl 
Keywords Annuity markets - Adverse selection - Overlapping generations · Demography

JEL Classification $\quad \mathrm{D} 52 \cdot \mathrm{D} 91 \cdot \mathrm{E} 10 \cdot \mathrm{J} 10$

\section{Introduction}

In a seminal paper, Yaari (1965) argues that in the face of life span uncertainty nonaltruistic individuals will fully annuitize their financial wealth. That is, they will invest all their savings in the annuity market, thereby insuring themselves against the risk of outliving their assets. However, empirical evidence has revealed that, despite the theoretical attractiveness of annuities, in practice people tend not to invest much in private annuity markets.

Several explanations for the low participation in annuity markets have been given in the literature. First of all, individuals may have a bequest motive, in that they wish to leave an inheritance to those they leave behind. If so, they will want to keep part of their financial assets outside the annuity market. Secondly, psychological factors may play a role. According to Cannon and Tonks (2008), people might feel uncomfortable to "bet on a long life". Investing in annuities only seems attractive if you expect to live long enough, as most of us would hate to die before having received at least our initial outlay back in periodic payments. Third, private annuity demand may be crowded out by a system of social security benefits.

A fourth explanation is that in reality annuities may not be actuarially fair, in the sense that individuals are insufficiently compensated for their risk of dying. This may be due to administrative costs and taxes or monopoly profits as a result of imperfect competition among annuity firms. The implications for macroeconomic growth and welfare of a loading factor on annuities proportional to the mortality rate are investigated in Heijdra and Mierau (2012). Another reason for annuity market imperfection is adverse selection. The healthier someone believes herself to be, the more likely she is to buy an annuity. As a consequence, low-mortality (and thus high-risk) individuals are overrepresented in the annuity market. Annuity firms will have to take this selection effect into account when pricing their products, as they will incur a loss if they offer a rate based on average survival probabilities in the population. The resulting higher prices (or lower return) will induce high-mortality (low-risk) individuals to invest less in the annuity market.

In this paper we abstract from bequest motives, administrative costs, and imperfect competition and focus on the adverse selection channel and the role of social annuities. Our work mainly builds on the foundations laid out by Heijdra and Reijnders (2009). They consider a continuous-time endogenous growth model with two types of agents differing in their health status acquired at birth, which is assumed to be private information. The equilibrium in the annuity market is then characterized by risk pooling among health types which induces the unhealthy agents to drop out of the market in the last stages of their lives. This pooling equilibrium is slightly dominated in welfare terms by a hypothetical full-information equilibrium (in which each health type receives its actuarially fair rate of return). 
We augment the work by Heijdra and Reijnders (2009) in several directions. First, rather than distinguishing only two types of agents, we model a continuum of health types. Second, instead of a employing a continuous-time model with endogenous growth we work with a discrete-time framework in which long-run growth is exogenously determined. This allows us to easily study what happens during the transition from one steady state to another.

Our main findings are as follows. First, we note that in the absence of private and social annuities there exist accidental bequests that must be redistributed somehow. When such bequests flow to the young, private saving is boosted as this constitutes an intergenerational transfer from dissavers to savers. In this so-called TY equilibrium the unhealthiest agents typically experience a binding borrowing constraint. Second, we demonstrate that when a private annuity market is opened up and information is perfect (the FI case), then all agents will purchase positive amounts of annuities. Third, in the more realistic case with asymmetric information (the AI scenario), the equilibrium in the market for annuities will be a pooling equilibrium in which the unhealthiest individuals face a self-imposed borrowing constraint and the other agents receive a common yield on their annuities. Fourth, both in the FI and AI cases the opening up of a private annuity market causes a 'tragedy of annuitization', as described in Heijdra et al. (2010). Intuitively, whilst it is individually optimal for agents to invest in annuities, it is not socially optimal. Agents of all health types are in the long run worse off compared to the benchmark case in which annuities are absent and accidental bequests are redistributed to the newly arrived young (TY). Fifth, the introduction of a mandatory social annuity system, while providing a 'fairer' rate of return than the private annuity market, reduces steady-state welfare even more. It aggravates the degree of adverse selection in the private annuity market and reduces the overall level of savings in the economy.

Other papers closely related to ours are Abel (1986), Walliser (2000), and Palmon and Spivak (2007). All three find that the introduction of social annuities accentuates the problem of adverse selection in the private annuity market. In Abel (1986) a two-period exogenous growth model is developed in which agents have privately known heterogenous mortality profiles and a bequest motive. Due to adverse selection, the rate of return on private annuities is less than actuarially fair. In this context, the introduction of a mandatory (demographically fair ${ }^{1}$ ) social security system further decreases the return on annuities in the steady state. Walliser (2000) builds on the work of Abel (1986), but calibrates his model with 75 instead of only 2 periods. The paper investigates the effects of pay-as-you-go social security benefits on private annuity demand and shows that privatization (i.e. elimination) of social security lowers the loading factor on annuities resulting from adverse selection. Finally, Palmon and Spivak (2007) argue that a modest social security system may reduce welfare in an adverse selection economy. The positive effect of providing agents with social

1 In order to avoid confusion we distinguish between individual and groupwise fairness of annuities. Following Abel (1986, pp. 1082, 1085) we deem annuities to be actually fair in an individual sense if its expected rate of return equals the rate on regular assets. We call an annuity demographically fair if its expected return based on a population average survival probability equals the return on regular assets. 
annuities at an demographically fair pooling rate is outweighed by the negative impact of increased adverse selection in the private annuity market.

In contrast to our work, however, both Walliser (2000) and Palmon and Spivak (2007) focus on the features of private annuity markets in isolation and do not take general equilibrium effects into account. Moreover, the latter fail to specify what happens to accidental bequests in the absence of annuities and therefore incorrectly conclude that private annuities are always welfare improving. Abel (1986) on the other hand does model a production sector with potentially endogenous factor prices and provides signs for the responses of key economic variables following a change in the rate of contribution to the social security system. Yet he does not give any insight in the magnitude of the effect on consumer welfare, nor how it may differ among risk types. Our contribution lies in providing a consistent general equilibrium framework for studying the main aspects related to life annuitization and social security. We are able to both analytically characterize the underlying mechanisms and to quantify their relative importance through a simulation with realistic parameter values.

The remainder of this paper is structured as follows. Section 2 describes the key features of the model in terms of the decisions made by households, firms, and the government sector. In Sect. 3 we introduce private annuity markets, while Sect. 4 shows the effects on general equilibrium and welfare when mandatory social annuities are added to the model. Section 5 concludes.

\section{Model}

\subsection{Consumers}

The population consists of overlapping generations of finitely-lived agents who are identical in every respect except for their health type. Agents live for a maximum of two periods, termed 'youth' (superscript $y$ ) and 'old age' $(o)$. At birth each agent learns her health status as proxied by the survival probability, $\mu$. This is where the difference between health types comes in: unhealthy agents have a higher risk of dying, and therefore a shorter expected life span (which equals $1+\mu$ periods). We assume that cohorts are sufficiently large such that there is no aggregate uncertainty and probabilities and frequencies coincide. For example, the fraction of young agents of type $\mu$ who die after the first period equals exactly $1-\mu$. Note that from the perspective of an individual agent, lifetime uncertainty is resolved at the start of the second period. When still alive, the agent will live for exactly one additional period.

Labour supply is exogenous. During youth the agent is fully employed while during old age labour supply is only a fraction $\lambda$ of the unit time endowment as a result of mandatory retirement $(0<\lambda<1)$. The expected lifetime utility of a representative agent of health type $\mu$ who is born in period $t$ is given by:

$$
\mathbb{E} \Lambda_{t}(\mu) \equiv U\left(C_{t}^{y}(\mu)\right)+\mu \beta U\left(C_{t+1}^{o}(\mu)\right)
$$

where $C_{t}^{y}(\mu)$ and $C_{t+1}^{o}(\mu)$ are consumption during youth and old age, respectively, $\beta$ is a parameter capturing pure time preference $(0<\beta<1)$, and $U(\cdot)$ is the felicity 
function:

$$
U(x) \equiv \frac{x^{1-1 / \sigma}-1}{1-1 / \sigma}, \quad \sigma>0 .
$$

This functional form is chosen for analytical convenience and it implies a constant intertemporal substitution elasticity, $\sigma$. We assume that the agent does not have a bequest motive such that she does not derive any utility from wealth that remains after her death.

The agent's periodic budget identities are given by:

$$
\begin{aligned}
C_{t}^{y}(\mu)+S_{t}(\mu) & =w_{t}+Z_{t}, \\
C_{t+1}^{o}(\mu) & =\lambda w_{t+1}+\left(1+r_{t+1}\right) S_{t}(\mu),
\end{aligned}
$$

where $w_{t}$ is the wage rate, $r_{t+1}$ is the rental rate of capital, $S_{t}(\mu)$ is the amount saved, and $Z_{t}$ denotes a lump-sum income transfer received from the government during youth. Since the government cannot observe an individual's health type, the transfer is the same for everybody. All workers are equally productive so the wage rate is common to all agents.

If annuity markets do not exist, agents cannot insure themselves against life span uncertainty. Their only option is to invest their savings in the capital market at a net rate of return $r_{t+1}$. Since there is a risk of dying after youth the agent may pass away before being able to consume her savings, thereby leaving an unintended bequest. It is not possible to borrow in the capital market, as the agent is not allowed to die indebted. Hence we impose the borrowing constraint $S_{t}(\mu) \geq 0$. Individuals who face a binding borrowing constraint have no better option than to consume their current and future endowments.

For unconstrained agents we can combine the two budget identities to obtain the consolidated budget constraint:

$$
C_{t}^{y}(\mu)+\frac{C_{t+1}^{o}(\mu)}{1+r_{t+1}}=w_{t}+Z_{t}+\frac{\lambda w_{t+1}}{1+r_{t+1}}
$$

That is, the present value of total consumption (left-hand side) should equal lifetime income or human wealth at birth (right-hand side). The representative agent maximizes life-time utility (1) subject to the budget constraint (5). The agent's optimal plans are fully characterized by:

$$
\begin{aligned}
C_{t}^{y}(\mu) & =\Phi\left(\mu, 1+r_{t+1}\right)\left[w_{t}+Z_{t}+\frac{\lambda w_{t+1}}{1+r_{t+1}}\right], \\
S_{t}(\mu) & =\left[1-\Phi\left(\mu, 1+r_{t+1}\right)\right]\left[w_{t}+Z_{t}\right]-\Phi\left(\mu, 1+r_{t+1}\right) \frac{\lambda w_{t+1}}{1+r_{t+1}}, \\
\frac{C_{t+1}^{o}(\mu)}{1+r_{t+1}} & =\left[1-\Phi\left(\mu, 1+r_{t+1}\right)\right]\left[w_{t}+Z_{t}+\frac{\lambda w_{t+1}}{1+r_{t+1}}\right],
\end{aligned}
$$


where $\Phi(\mu, x)$ is the marginal propensity to consume out of lifetime wealth during youth:

$$
\Phi(\mu, x) \equiv \frac{1}{1+(\mu \beta)^{\sigma} x^{\sigma-1}}, \quad(0<\Phi(\mu, x)<1)
$$

We find that consumption during youth and the present value of consumption during old age are proportional to human wealth at birth. The level of savings depends positively on the total income received during youth and negatively on the discounted value of future wage income.

The optimal consumption choices can be illustrated with the aid of Fig. 1. The line labeled HBC is the household budget constraint as given in (5). It passes through the income endowment point A which is the same for all individuals. Agents wish to consume such that the marginal rate of substitution between current and future consumption is equated to the survival-adjusted gross interest rate:

$$
\frac{U^{\prime}\left(C_{t}^{y}(\mu)\right)}{\beta U^{\prime}\left(C_{t+1}^{o}(\mu)\right)}=\mu\left(1+r_{t+1}\right) .
$$

For the felicity function employed in this paper, the Euler equation is a straight line from the origin with a slope that depends positively on the agents survival probability, $\mu$. In the diagram, $\operatorname{EE}\left(\mu_{h}\right)$ and $\operatorname{EE}\left(\mu_{l}\right)$ denote the Euler equations for, respectively, the healthiest and unhealthiest types of agents. The former types consume at point $\mathrm{B}$ which is attained by saving during youth. The latter types, however, would like to consume at point $\mathrm{C}$ but this point is unattainable because it violates the borrowing constraint. The best such an agent can do is to consume at the income endowment point A. ${ }^{2}$

With a continuum of health types, it thus follows that in general not all agents are net savers in the absence of annuities. In the case drawn in Fig. 1, there exists a marginal health type $\mu_{b c, t}$ such that $\mathrm{EE}\left(\mu_{b c, t}\right)$ passes through the income endowment point $\mathrm{A}$. Agents of this type optimally choose not to save anything during youth. Hence, all relatively healthy agents $\left(\mu_{b c, t} \leq \mu \leq \mu_{h}\right)$ are unconstrained whereas all relatively unhealthy agents $\left(\mu_{l} \leq \mu<\mu_{b c, t}\right)$ are borrowing constrained and are "bunching" at the income endowment point A.

\subsection{Demography}

Let $h(\mu)$ denote the probability density function of health types in a given cohort upon its arrival. Then the distribution of agents in the cohort born at time $t$ can be written as:

$$
L_{t}(\mu) \equiv h(\mu) L_{t}
$$

\footnotetext{
2 We have drawn Fig. 1 such that there are some borrowing-constrained individuals in equilibrium. This case is consistent with the calibrated example used in this paper. See column (a) in Table 2.
} 


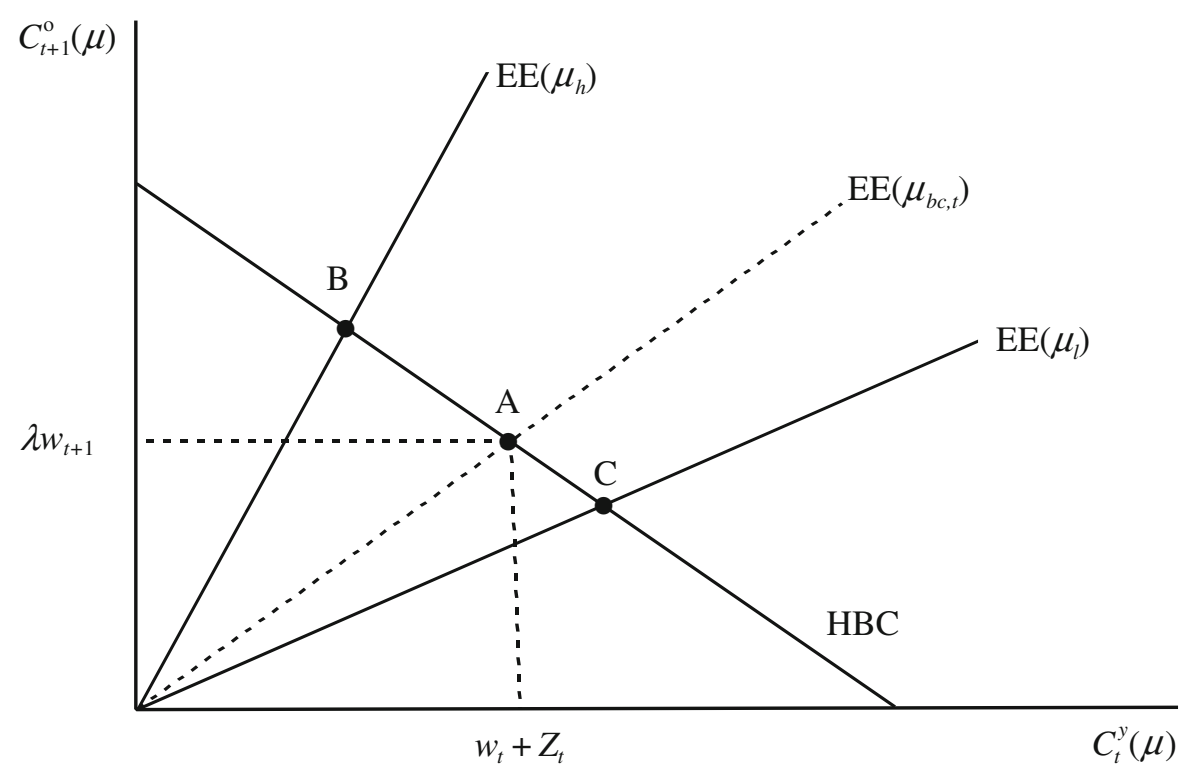

Fig. 1 Choices of a $\mu$-type individual in the absence of annuities

where $L_{t}$ is the total size of the cohort. By definition, $\int_{\mu_{l}}^{\mu_{h}} h(\mu) d \mu=\int_{\mu_{l}}^{\mu_{h}} d H(\mu)=1$ where $H(\mu)$ is the cumulative density function. The density of $\mu$-type agents alive at time $t$ is given by $P_{t}(\mu) \equiv \mu L_{t-1}(\mu)+L_{t}(\mu)$. Assuming that newborn cohorts evolve according to $L_{t}=(1+n) L_{t-1}$ (with $n>-1$ ) we thus find that:

$$
P_{t}(\mu)=\frac{1+\mu+n}{1+n} L_{t}(\mu) .
$$

The total population alive in period $t$ is obtained by aggregating over health types:

$$
P_{t} \equiv \int_{\mu_{l}}^{\mu_{h}} P_{t}(\mu) d \mu=\frac{1+\bar{\mu}+n}{1+n} L_{t},
$$

where $\bar{\mu} \equiv \int_{\mu_{l}}^{\mu_{h}} \mu h(\mu) d \mu$ is the average survival rate in the population as a whole.

\subsection{Government}

In the absence of annuity markets we have to make an assumption about how the accidental bequests left by the dead are redistributed among the agents who are still alive. We therefore introduce a government sector which collects the bequests and uses them to finance lump-sum income transfers $Z_{t}$ to the young. ${ }^{3}$ The government budget constraint is given by:

\footnotetext{
3 This is a standard assumption in the economic literature when agents do not have a bequest motive. See for example Pecchenino and Pollard (1997).
} 


$$
\left(1+r_{t}\right) \int_{\mu_{b c, t}}^{\mu_{h}}(1-\mu) L_{t-1}(\mu) S_{t-1}(\mu) d \mu=L_{t} Z_{t} .
$$

That is, the total amount of accidental bequests (left-hand side) equals the sum of income transfers (right-hand side).

\subsection{Production}

The production side of this closed economy features a large number of perfectly competitive firms who produce a homogeneous commodity. The technology is represented by the following Cobb-Douglas production function:

$$
Y_{t}=\Omega_{0} K_{t}^{\varepsilon} N_{t}^{1-\varepsilon}, \quad 0<\varepsilon<1,
$$

where $Y_{t}$ is total output, $\Omega_{0}>0$ is an exogenously given index of general factor productivity, $K_{t}$ is the aggregate capital stock, and $N_{t} \equiv L_{t}+\bar{\mu} \lambda L_{t-1}$ is the labour force. By defining $y_{t} \equiv Y_{t} / N_{t}$ and $k_{t} \equiv K_{t} / N_{t}$ we can write the intensive-form production function as:

$$
y_{t}=\Omega_{0} k_{t}^{\varepsilon} .
$$

Profit-maximizing behaviour of firms yields the following factor demand equations:

$$
\begin{aligned}
r_{t}+\delta & =\varepsilon \Omega_{0} k_{t}^{\varepsilon-1}, \\
w_{t} & =(1-\varepsilon) \Omega_{0} k_{t}^{\varepsilon},
\end{aligned}
$$

where $\delta$ is the constant rate of depreciation of the capital stock $(0<\delta<1)$.

The general model without annuities is fully characterized by the following fundamental difference equation:

$$
k_{t+1}=\phi_{1}^{T Y}\left(r_{t+1}\right)\left[w_{t}+Z_{t}\right]-\phi_{2}^{T Y}\left(r_{t+1}\right) \frac{\lambda w_{t+1}}{1+r_{t+1}},
$$

where $\phi_{1}^{T Y}\left(r_{t+1}\right)$ and $\phi_{2}^{T Y}\left(r_{t+1}\right)$ are given by:

$$
\begin{aligned}
\phi_{1}^{T Y}\left(r_{t+1}\right) & \equiv \frac{1}{1+n+\lambda \bar{\mu}} \int_{\mu_{b c, t}}^{\mu_{h}}\left[1-\Phi\left(\mu, 1+r_{t+1}\right)\right] h(\mu) d \mu, \\
\phi_{2}^{T Y}\left(r_{t+1}\right) & \equiv \frac{1}{1+n+\lambda \bar{\mu}} \int_{\mu_{b c, t}}^{\mu_{h}} \Phi\left(\mu, 1+r_{t+1}\right) h(\mu) d \mu .
\end{aligned}
$$

Equation (19) is obtained by imposing equilibrium in the savings market and using the cohort size evolutions described in Sect. 2.2. At time $t$ the predetermined capital 
Table 1 Structural parameters and functions

\begin{tabular}{lll}
\hline$\beta$ & Time preference factor & 0.4128 \\
$\sigma$ & Intertemporal substitution elasticity & 0.7000 \\
$n$ & Population growth factor & 0.4889 \\
$\varepsilon$ & Capital efficiency parameter & 0.2750 \\
$\Omega_{0}$ & Scale factor production function & 2.4312 \\
$\delta$ & Capital depreciation factor & 0.9158 \\
$\lambda$ & Mandatory retirement parameter & 0.6250 \\
$h(\mu)$ & PDF of the survival probability & Uniform on $\left[\mu_{l}, \mu_{h}\right]$ \\
$\mu_{l}$ & Survival rate of the unhealthiest & 0.0500 \\
$\mu_{h}$ & Survival rate of the unhealthiest & 0.9500 \\
\hline
\end{tabular}

intensity, $k_{t}$, pins down $r_{t}, w_{t}$, and $Z_{t}$, so that (19) in combination with (17) and (18) constitutes an implicit function determining $k_{t+1}, r_{t+1}$, and $w_{t+1}$. The cut-off value $\mu_{b c, t}$ is such that $S_{t}\left(\mu_{b c, t}\right)=0$. From these variables $Z_{t+1}$ can be computed. In the steady state we have $k_{t+1}=k_{t}=\hat{k}$ such that the level of output per worker $\hat{y}$ is constant. As a consequence, the long-run rate of economic growth over and above population growth equals zero, which is a standard result in an exogenous growth model without technological process.

Throughout this paper we visualize and quantify the properties of the model by means of simulations with realistic parameter values. The main structural parameters are summarized in Table 1. The calibration was done as follows. In step 1, we postulate plausible values for the intertemporal substitution elasticity $(\sigma=0.7)$, the efficiency parameter of capital $(\varepsilon=0.275)$, the annual capital depreciation rate $\left(\delta_{a}=0.06\right)$, the annual growth rate of the population $\left(n_{a}=0.01\right)$ and choose a realistic target annual steady-state interest rate $\left(\hat{r}_{a}=0.05\right)$. Taken together these parameters ensure that the annual steady-state capital-output ratio is $\hat{K} / \hat{Y}=\varepsilon /\left(\hat{r}_{a}+\delta_{a}\right)=2.5$. In step 2, we fix the time dimension by assuming that each period lasts for 40 years. The values for $n$, $\delta$, and $\hat{r}$ follow readily from this. ${ }^{4}$ We assume that mandatory retirement takes place at age 65 , which yields the value for $\lambda$ in Table 1 . Furthermore, we postulate a distribution for the probability of surviving into the second period and note that life expectancy at birth of a $\mu$-type agent is given by $40(1+\mu)$ in years. In step 3 we choose $\Omega_{0}$ such that $\hat{y}=1$ in the initial steady state. This also pins down the steady-state values for $\hat{w}$ and $\hat{k}$. Finally, in step 4 we solve for steady-state transfers $\hat{Z}$, the discount factor $\beta$, and the cut-off survival level for the borrowing constraint $\hat{\mu}_{b c}$ [satisfying $S\left(\hat{\mu}_{b c}\right)=0$ ] such that a consistent general equilibrium solution is obtained. To interpret the resulting value for $\beta$ we note that $\rho_{a}=\beta^{-1 / 40}-1=0.0237$ represents the annual rate of time preference. In view of the fact that the annual rate of interest is $\hat{r}_{a}=0.05$ agents in this economy are relatively patient.

The key features of the steady-state equilibrium that is attained in the absence of private and social annuities and with accidental transfers flowing to the young (abbreviated as TY) are reported in column (a) of Table 2. As was enforced by

$\overline{4 \text { In particular, } n=\left(1+n_{a}\right)^{40}}-1, \delta=1-\left(1-\delta_{a}\right)^{40}$, and $\hat{r}=\left(1+r_{a}\right)^{40}-1$. 
Table 2 Allocation and welfare

\begin{tabular}{|c|c|c|c|c|c|c|}
\hline & (a) $\mathrm{TY}$ & (b) FI & (c) AI & $\begin{array}{l}\text { (d) SA } \\
\theta=0.01\end{array}$ & $\begin{array}{l}\text { (e) SA } \\
\theta=0.02\end{array}$ & $\begin{array}{l}\text { (f) SA } \\
\theta=0.03\end{array}$ \\
\hline$\hat{y}$ & 1.0000 & 0.9638 & 0.9473 & 0.9395 & 0.9318 & 0.9247 \\
\hline$\hat{k}$ & 0.0395 & 0.0346 & 0.0325 & 0.0315 & 0.0306 & 0.0297 \\
\hline$\%$ Q1 & 3.62 & 9.10 & 5.86 & 3.25 & 1.23 & 0.11 \\
\hline$\% \mathrm{Q} 2$ & 19.66 & 20.51 & 20.66 & 17.25 & 13.43 & 9.14 \\
\hline$\% \mathrm{Q} 3$ & 32.96 & 30.66 & 32.05 & 28.94 & 25.46 & 21.52 \\
\hline$\%$ Q4 & 43.76 & 39.73 & 41.43 & 38.56 & 35.35 & 31.69 \\
\hline$\% \mathrm{SAS}$ & & & & 12.00 & 24.53 & 37.54 \\
\hline$\hat{r}$ & 6.0400 & 6.7500 & 7.1079 & 7.2840 & 7.4632 & 7.6348 \\
\hline$\hat{r}^{a}$ & 0.0500 & 0.0525 & 0.0537 & 0.0543 & 0.0548 & 0.0554 \\
\hline$\hat{w}$ & 0.7250 & 0.6988 & 0.6868 & 0.6811 & 0.6756 & 0.6704 \\
\hline$\hat{Z}$ & 0.1146 & & & & & \\
\hline$H\left(\hat{\mu}_{b c}\right)$ & 0.1029 & 0.0000 & 0.0533 & 0.0999 & 0.1556 & 0.2217 \\
\hline$\hat{\bar{\mu}}^{p}$ & & & 0.6418 & 0.6597 & 0.6802 & 0.7035 \\
\hline$\hat{c}^{y}$ & 0.6351 & 0.5261 & 0.5193 & 0.5161 & 0.5128 & 0.5098 \\
\hline$\% \mathrm{Q} 1$ & 26.98 & 26.56 & 26.78 & 26.70 & 26.57 & 26.35 \\
\hline$\%$ Q2 & 25.50 & 25.44 & 25.40 & 25.43 & 25.48 & 25.56 \\
\hline$\%$ Q3 & 24.26 & 24.45 & 24.34 & 24.37 & 24.41 & 24.49 \\
\hline$\%$ Q4 & 23.26 & 23.56 & 23.47 & 23.49 & 23.54 & 23.60 \\
\hline$\hat{c}^{o}$ & 0.3094 & 0.3892 & 0.3824 & 0.3792 & 0.3760 & 0.3731 \\
\hline$\%$ Q1 & 4.05 & 8.80 & 3.88 & 3.98 & 4.21 & 4.66 \\
\hline$\% \mathrm{Q} 2$ & 14.98 & 20.16 & 14.88 & 14.87 & 14.83 & 14.77 \\
\hline$\%$ Q3 & 30.81 & 30.65 & 30.81 & 30.77 & 30.70 & 30.56 \\
\hline$\% \mathrm{Q} 4$ & 50.16 & 40.40 & 50.44 & 50.38 & 50.26 & 50.02 \\
\hline $\mathbb{E} \hat{\Lambda}\left(\mu_{l}\right)$ & -0.2010 & -0.3913 & -0.4287 & -0.4439 & -0.4608 & -0.4784 \\
\hline $\mathbb{E} \hat{\Lambda}\left(\mu_{1}\right)$ & -0.2717 & -0.4107 & -0.4858 & -0.4931 & -0.4994 & -0.5042 \\
\hline $\mathbb{E} \hat{\Lambda}\left(\mu_{2}\right)$ & -0.2884 & -0.4335 & -0.4830 & -0.4911 & -0.4984 & -0.5043 \\
\hline $\mathbb{E} \hat{\Lambda}\left(\mu_{3}\right)$ & -0.2789 & -0.4595 & -0.4555 & -0.4643 & -0.4726 & -0.4795 \\
\hline $\mathbb{E} \hat{\Lambda}\left(\mu_{h}\right)$ & -0.2540 & -0.4884 & -0.4135 & -0.4231 & -0.4322 & -0.4401 \\
\hline
\end{tabular}

Here $\% \mathrm{Q} j$ denotes the share accounted for by population quartile $j$ of the variable directly above it. $\%$ SAS is the share owned by the social annuity system. $\mu_{j}$ is the upper bound for $\mu$ in quartile $j$, i.e. $H\left(\mu_{j}\right)=j / 4$ for $j \in\{1,2,3,4\}$ and $\mu_{4}=\mu_{h} . \mathbb{E} \hat{\Lambda}\left(\mu_{j}\right)$ gives expected utility for an agent with health type $\mu_{j}$

the calibration procedure, output per worker is equal to unity and the steady-state interest rate is five percent on an annual basis. Steady-state transfers to the young amount to $\hat{Z}=0.1146$ which is almost sixteen percent of wage income during youth. Steady-state consumption per worker by the young and surviving old are given by, respectively $\hat{c}^{y} \equiv\left[\int_{\mu_{l}}^{\mu_{h}} L_{t}(\mu) \hat{C}^{y}(\mu) d \mu\right] / N_{t}$ and $\hat{c}^{o} \equiv\left[\int_{\mu_{l}}^{\mu_{h}} \mu L_{t-1}(\mu) \hat{C}^{o}(\mu) d \mu\right] / N_{t}$. Whilst the distribution over quartiles is rather even for youth consumption, it is very skewed for old-age consumption with the healthiest quartile accounting for half of 
(a)

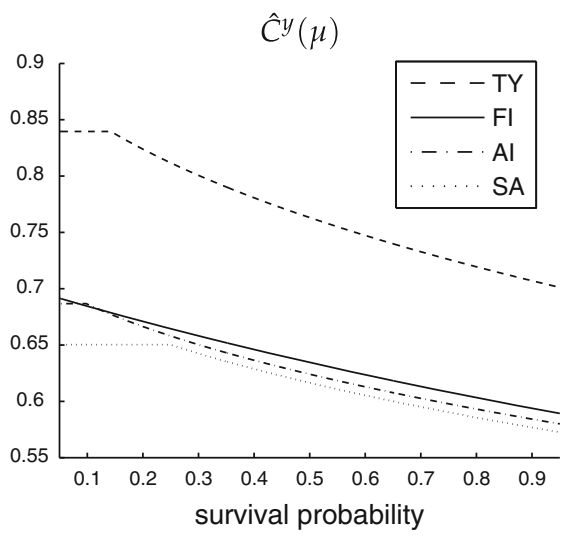

(c)

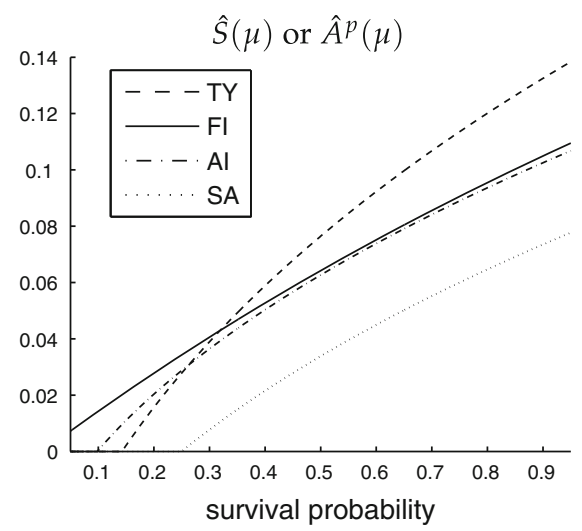

(b)

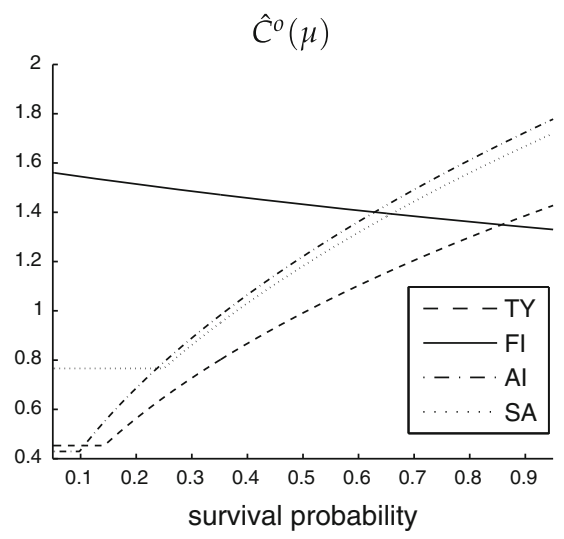

(d)

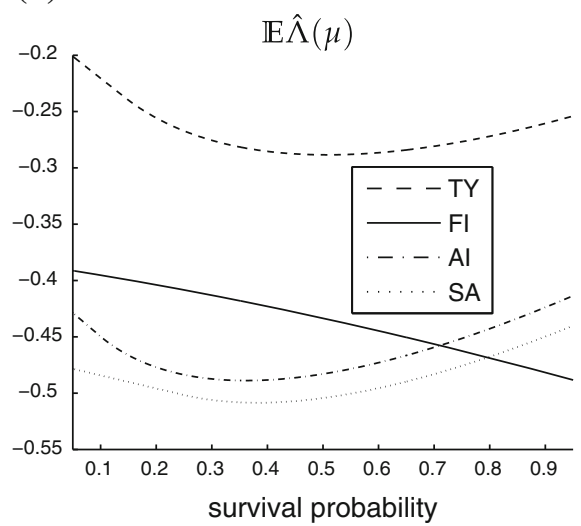

Fig. 2 Steady-state profiles. (a) Youth consumption $\hat{C}^{y}(\mu)$, (b) old-age consumption $\hat{C}^{o}(\mu)$, (c) saving/annuity demand $\hat{S}(\mu)$ or $\hat{A}^{p}(\mu)$, (d) expected utility $\mathbb{E} \hat{\Lambda}(\mu)$

consumption by the old. More than ten percent of the agents encounter a binding borrowing constraint $\left[H\left(\hat{\mu}_{b c}\right)=0.1029\right]$. The wealth distribution by quartiles (as evidenced by capital ownership) is very uneven, with the unhealthiest and healthiest quartiles owning, respectively, 3.62 and $43.76 \%$ of the capital stock.

In Fig. 2 the steady-state health profiles for youth- and old-age consumption, saving, and expected utility at birth are illustrated-see the dashed lines. The horizontal segments in panels $(\mathrm{a}-\mathrm{c})$ are the realizations for the (borrowing-constrained) endowment consumers. As expected from our theoretical discussion above, for unconstrained agents youth consumption is falling in health whilst the opposite holds for old-age consumption which, like saving, is increasing in health. Interestingly, expected utility is a non-monotonic function of health. ${ }^{5}$

5 The downward sloping part has been noted in the literature on health economics. It results from the fact that, for $0<\sigma<1$ and $0<x<1$, the felicity function satisfies $U(x)<0$ so that higher life expectancy translates into lower expected lifetime utility. The upward sloping part follows from the fact that old-age 


\section{Private Annuity Markets}

Now consider the introduction of a private annuity market in this economy. A (life) annuity is an asset which pays a stipulated return contingent upon survival of the annuitant. In order to compete with other investment products, annuities have to provide a rate of return which exceeds the market rate of interest to compensate for the risk of death. The annuity firm is willing to pay this additional return on savings as it is held free of any obligation after the annuitant has died. Conversely, an agent who sells an actuarial note gets a life-insured loan and will have her debts acquitted when she dies prematurely. Hence, an agent who exclusively uses the annuity market for financial transactions will never die indebted or leave an (unintended) bequest.

It is important to note that an annuity market constitutes just another type of redistribution scheme. Instead of channeling funds from the dead to the newly arrived young by means of lump sum transfers as above, an annuity market redistributes money from the dead to those that survive by offering a premium over and above the rental rate of capital. Therefore, the macroeconomic and welfare effects of introducing a private annuity market are not a priori clear.

\subsection{Full Information Equilibrium}

We make the following assumptions about the private market for annuities:

(A1) The annuity market is perfectly competitive. There is a large number of risk neutral firms offering annuities to individuals, and firms can freely enter or exit the market.

(A2) Annuity firms do not use up any real resources.

As a consequence of these assumptions the expected profit of each annuity firm is zero. We start by considering the benchmark case in which health status is public information. In the Full Information equilibrium in the annuity market (abbreviated as FI) each health type receives its actuarially fair rate of return and achieves perfect insurance against life span uncertainty. There is market segmentation in the sense that there is a separate market for each type of agent.

Let $A_{t}^{p}(\mu)$ denote the private annuity holdings of an agent of health type $\mu$. As the net rate of return on annuities exceeds the rental rate of capital, all agents will completely annuitize their wealth. This is the famous result found by Yaari (1965).

An annuity firm sells annuities to agents of health type $\mu$ that pay a net rate of return $r_{t+1}^{p}(\mu)$ contingent upon survival of the annuitant. The firm invests the proceeds in the capital market, thus earning a rate of return $r_{t+1}$. Since some of its clients will die young and will subsequently lose their claim at an early stage, the annuity firm can redistribute their assets among the surviving clientele. The zero-profit conditions for the annuity market are therefore given by:

Footnote 5 continued

consumption for the healthiest exceeds unity so that felicity becomes positive. Of course, the location of the slope change depends on the scaling of the variables. 


$$
\left(1+r_{t+1}\right) L_{t}(\mu) A_{t}^{p}(\mu)=\mu\left(1+r_{t+1}^{p}(\mu)\right) L_{t}(\mu) A_{t}^{p}(\mu), \quad \mu \in\left[\mu_{l}, \mu_{h}\right] .
$$

That is, the gross return earned on the amount of savings collected from clients of health type $\mu$ in period $t$ (left-hand side) should equal the (expected) claim originating from surviving clients of health type $\mu$ in period $t+1$. It follows that:

$$
1+r_{t+1}^{p}(\mu)=\frac{1+r_{t+1}}{\mu}, \quad \mu \in\left[\mu_{l}, \mu_{h}\right] .
$$

Note that $r_{t+1}^{p}(\mu)$ is decreasing in the survival probability, i.e. unhealthy agents earn a higher gross rate of return on their investments in the annuity market than do healthy agents.

Since $0<\mu_{l}<\mu_{h}<1$ it follows that the interest rate on annuities exceeds the rate of return on capital for all agents, i.e. $r_{t+1}^{p}(\mu)>r_{t+1}$ for all $\mu \in\left[\mu_{l}, \mu_{h}\right]$. As a result rational agents will fully annuitize their savings (as was asserted above) so that the lifetime budget constraint is given by:

$$
C_{t}^{y}(\mu)+\frac{C_{t+1}^{o}(\mu)}{1+r_{t+1}^{p}(\mu)}=w_{t}+\frac{\lambda w_{t+1}}{1+r_{t+1}^{p}(\mu)} .
$$

Comparing the TY and FI scenarios [as described by, respectively, (5) and (22)], we find that for the latter case accidental bequests (and thus transfers from the government) are absent and the relevant return is type dependent. The consumption Euler equation for the FI case is given by:

$$
\frac{U^{\prime}\left(C_{t}^{y}(\mu)\right)}{\beta U^{\prime}\left(C_{t+1}^{o}(\mu)\right)}=\mu\left(1+r_{t+1}^{p}(\mu)\right)=1+r_{t+1} .
$$

With actuarially fair annuities and full annuitization the marginal rate of substitution between current and future consumption is equated to the gross interest factor on capital. The mortality rate does not feature in this expression because agents are fully insured against the unpleasant aspects of lifetime uncertainty. This celebrated result was first proposed by Yaari (1965) in a continuous-time model.

By combining the lifetime budget constraint (22) and the Euler equation (23) we obtain the following expressions for consumption during youth, the demand for annuities, and old-age consumption:

$$
\begin{gathered}
C_{t}^{y}(\mu)=\Phi\left(\mu,\left(1+r_{t+1}\right) / \mu\right)\left[w_{t}+\frac{\lambda \mu w_{t+1}}{1+r_{t+1}}\right], \\
A_{t}^{p}(\mu)=\left[1-\Phi\left(\mu,\left(1+r_{t+1}\right) / \mu\right)\right] w_{t}-\Phi\left(\mu,\left(1+r_{t+1}\right) / \mu\right) \frac{\lambda \mu w_{t+1}}{1+r_{t+1}}, \\
\frac{\mu C_{t+1}^{o}(\mu)}{1+r_{t+1}}=\left[1-\Phi\left(\mu,\left(1+r_{t+1}\right) / \mu\right)\right]\left[w_{t}+\frac{\lambda \mu w_{t+1}}{1+r_{t+1}}\right],
\end{gathered}
$$




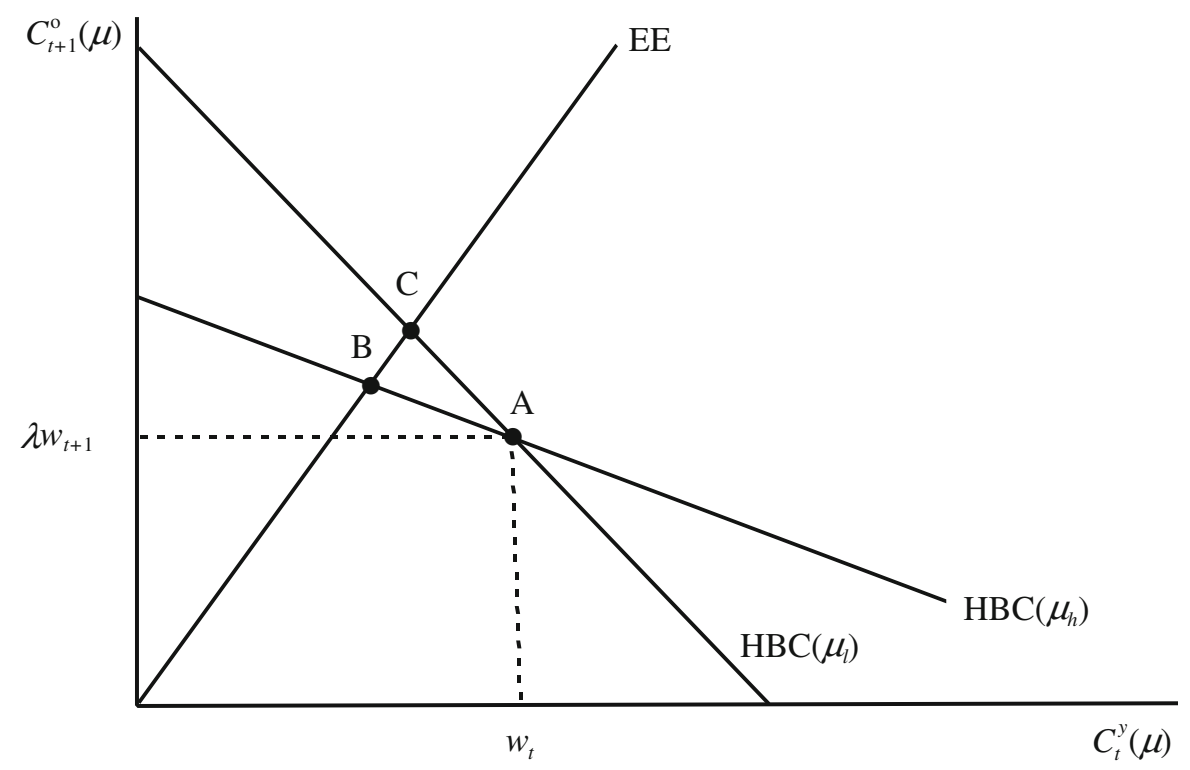

Fig. 3 Choices of a $\mu$-type individual with perfect annuities

where $\Phi(\mu, x)$ is defined in (9) above. The optimal consumption choices can be illustrated with the aid of Fig. 3. The line labeled EE is the Euler equation (23) which is the same for all health types. In contrast, there exists a continuum of $\operatorname{HBC}(\mu)$ lines passing though the income endowment point A. The lines labeled $\operatorname{HBC}\left(\mu_{l}\right)$ and $\operatorname{HBC}\left(\mu_{h}\right)$ depict the lifetime budget constraints faced by, respectively, the unhealthiest and healthiest individuals. It follows that the unhealthiest types consume at point $\mathrm{C}$ whilst the healthiest choose point $\mathrm{B}$. Throughout the population consumption patterns are located along the line segment BC.

Under the maintained hypothesis that a non-trivial macroeconomic equilibrium exists, two qualitative conclusions can already be drawn on the basis of Fig. 3. First, since the endowment point is type-independent, all individuals must be net savers during youth. (The opposite case with all agents being net borrowers is inconsistent with a positive capital stock in a closed-economy equilibrium.) Whereas the unhealthiest agents in the population tend to face a binding borrowing constraint in a world without annuities (see above), these same agents express a positive demand for annuities in the FI scenario because the rate they receive on such instruments in case they survive into old age is quite high [i.e. $\mathrm{HBC}\left(\mu_{l}\right)$ is rather steep]. Second, just as the savings function is in the TY case, the demand for annuities in the FI scenario is increasing in health type.

The fundamental difference equation for the FI model is given by:

$$
k_{t+1}=\phi_{1}^{F I}\left(r_{t+1}\right) w_{t}-\phi_{2}^{F I}\left(r_{t+1}\right) \frac{\lambda w_{t+1}}{1+r_{t+1}}
$$

where $\phi_{1}^{F I}\left(r_{t+1}\right)$ and $\phi_{2}^{F I}\left(r_{t+1}\right)$ are defined as follows: 


$$
\begin{aligned}
\phi_{1}^{F I}\left(r_{t+1}\right) & \equiv \frac{1}{1+n+\lambda \bar{\mu}} \int_{\mu_{l}}^{\mu_{h}}\left[1-\Phi\left(\mu,\left(1+r_{t+1}\right) / \mu\right)\right] h(\mu) d \mu, \\
\phi_{2}^{F I}\left(r_{t+1}\right) & \equiv \frac{1}{1+n+\lambda \bar{\mu}} \int_{\mu_{l}}^{\mu_{h}} \mu \Phi\left(\mu,\left(1+r_{t+1}\right) / \mu\right) h(\mu) d \mu .
\end{aligned}
$$

The existence of a well-defined macroeconomic equilibrium is confirmed by the results reported in column (b) of Table 2. Compared to the TY case, output, the wage rate, and the capital stock are lower and the interest rate is higher under the FI scenario. The intuition behind these results is explained in Sect. 3.3 below.

In Fig. 2 the steady-state health profiles for youth and old-age consumption, annuity demand, and expected utility at birth are depicted-see the solid lines. Youth consumption, old-age consumption, and expected utility are decreasing in health whilst the opposite holds for the demand for annuities.

\subsection{Asymmetric Information Equilibrium}

The following assumptions are added to the ones above:

(A3) Health status is private information of the annuitant. The distribution of health types in the population and the corresponding survival probabilities are common knowledge.

(A4) Annuitants can buy multiple annuities for different amounts and from different annuity firms. Individual annuity firms cannot monitor an annuitant's holdings with other firms.

Under these assumptions, the Asymmetric Information (AI) equilibrium in the annuity market is a pooling equilibrium. The existence of this pooling equilibrium depends critically on (A3): as annuity firms cannot observe their customers' health type, they will offer a single rate of return which applies to all their clients. They can exploit their knowledge about the distribution of health types in the population in setting this common annuity rate. Note that if (A4) would not hold then annuity firms could indirectly deduce an agent's health type by the amount of wealth she has invested. Healthy individuals tend to save more, which exacerbates the degree of adverse selection in the annuity market.

Our conclusion that a pooling equilibrium will prevail in the annuity market appears opposite to that of Rothschild and Stiglitz (1976), who show that a pooling equilibrium does not exist in an insurance market. However, their result relies heavily on the assumption that customers can buy only one insurance contract such that the insurer sets both price and quantity. They admit themselves that this may be an objectionable assumption in some cases, and Walliser (2000) argues that it indeed does not apply to the annuity market. First of all, monitoring the receipts of annuity payments from other annuity firms would be very difficult. Secondly, in contrast to other types of insurance, the death of the annuitant ends the liability of the annuity firm instead of creating it. Hence, withholding payments and investigating compliance is not feasible. 
We therefore believe it to be justified to assume that the annuity firm can only control the rate of return on annuities and cannot set prices and quantities simultaneously in order to obtain full information revelation.

An implicit assumption in the model is that annuitants cannot credibly signal their health status to the market. In the absence of cheap and credible medical tests, this is not a strong assumption at all. When asked about her health type, each individual has a clear incentive to claim to be unhealthy in order to get the highest possible return in a separated market. However, firms know this and will therefore not believe the annuitant's claim. Hence, even though part of their clientele tells the truth, the fact that some have an incentive to lie is enough for the annuity firm to assume that everyone will be a fraud.

We now turn to the determination of the pooled annuity rate, denoted by $\bar{r}_{t+1}^{p}$. As this rate will apply to agents of all health types it does not depend on $\mu$. Assume that all agents with $\mu \in\left[\mu_{b c, t}, \mu_{h}\right]$ purchase annuities, i.e. are net savers. Then the zero-profit condition for the annuity market is given by:

$$
\left(1+r_{t+1}\right) \int_{\mu_{b c, t}}^{\mu_{h}} L_{t}(\mu) A_{t}^{p}(\mu) d \mu=\left(1+\bar{r}_{t+1}^{p}\right) \int_{\mu_{b c, t}}^{\mu_{h}} \mu L_{t}(\mu) A_{t}^{p}(\mu) d \mu .
$$

As in the case of a full-information equilibrium the gross return earned on the amount of savings collected from clients in period $t$ (left-hand side) should equal the (expected) claim originating from surviving clients in period $t+1$. It follows that:

$$
1+\bar{r}_{t+1}^{p}=\frac{1+r_{t+1}}{\bar{\mu}_{t}^{p}}
$$

where $\bar{\mu}_{t}^{p}$ denotes the asset-weighted average survival rate of annuity purchasers:

$$
\bar{\mu}_{t}^{p} \equiv \int_{\mu_{b c, t}}^{\mu_{h}} \mu \xi_{t}(\mu) d \mu, \quad \xi_{t}(\mu) \equiv \frac{A_{t}^{p}(\mu) h(\mu)}{\int_{\mu_{b c, t}}^{\mu_{h}} A_{t}^{p}(\mu) h(\mu) d \mu}, \quad \mu \in\left[\mu_{b c, t}, \mu_{h}\right]
$$

This result has also been found in a partial equilibrium context by Sheshinski (2008) and relates to the linear equilibrium concept of Pauly (1974). As noted by Walliser (2000), it can alternatively be interpreted as a Nash equilibrium among annuity firms in which each firm that deviates from the zero-profit price incurs a loss.

The lifetime budget constraint for annuitants is given by:

$$
C_{t}^{y}(\mu)+\frac{C_{t+1}^{o}(\mu)}{1+\bar{r}_{t+1}^{p}}=w_{t}+\frac{\lambda w_{t+1}}{1+\bar{r}_{t+1}^{p}}
$$

where $\bar{r}_{t+1}^{p}$ is defined in (29) above. Utility maximization results in the following expression for the consumption Euler equation: 


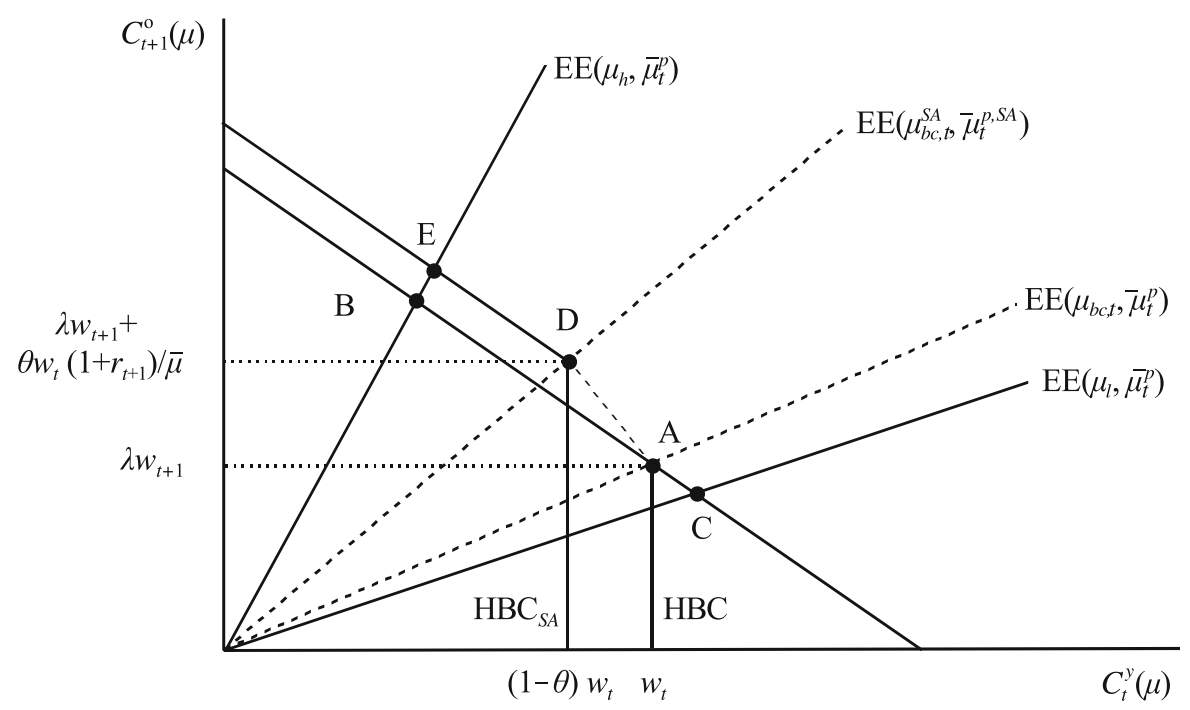

Fig. 4 Choices of a $\mu$-type individual with imperfect annuities

$$
\frac{U^{\prime}\left(C_{t}^{y}(\mu)\right)}{\beta U^{\prime}\left(C_{t+1}^{o}(\mu)\right)}=\mu\left(1+\bar{r}_{t+1}^{p}\right)=\frac{\mu}{\bar{\mu}_{t}^{p}}\left(1+r_{t+1}\right) .
$$

In the AI case the marginal rate of substitution between current and future consumption is equated to the expected gross return on pooled annuities. The mortality rate still features in this expression because agents are imperfectly insured against the unpleasant aspects of lifetime uncertainty.

By combining the lifetime budget constraint (31) and the Euler equation (32) we obtain the following expressions for consumption during youth, the demand for annuities, and old-age consumption:

$$
\begin{gathered}
C_{t}^{y}(\mu)=\Phi\left(\mu,\left(1+r_{t+1}\right) / \bar{\mu}_{t}^{p}\right)\left[w_{t}+\frac{\lambda \bar{\mu}_{t}^{p} w_{t+1}}{1+r_{t+1}}\right], \\
A_{t}^{p}(\mu)=\left[1-\Phi\left(\mu,\left(1+r_{t+1}\right) / \bar{\mu}_{t}^{p}\right)\right] w_{t} \\
-\Phi\left(\mu,\left(1+r_{t+1}\right) / \bar{\mu}_{t}^{p}\right) \frac{\lambda \bar{\mu}_{t}^{p} w_{t+1}}{1+r_{t+1}}, \\
\frac{\bar{\mu}_{t}^{p} C_{t+1}^{o}(\mu)}{1+r_{t+1}}=\left[1-\Phi\left(\mu,\left(1+r_{t+1}\right) / \bar{\mu}_{t}^{p}\right)\right]\left[w_{t}+\frac{\lambda \bar{\mu}_{t}^{p} w_{t+1}}{1+r_{t+1}}\right],
\end{gathered}
$$

where $\Phi(\mu, x)$ is defined in (9) above. In Fig. 4 we illustrate the case (confirmed for the calibrated model) in which not all agents purchase annuities in the AI equilibrium, i.e. $\mu_{b c, t}>\mu_{l}$. The household budget constraint faced by all agents alike is given by HBC whilst the endowment point is at point A. For given values of $\bar{\mu}_{t}^{p}$ and $1+r_{t+1}$, the Euler equation (32) depends on the agents survival probability, with $\operatorname{EE}\left(\mu_{h}\right)$ and $\mathrm{EE}\left(\mu_{l}\right)$ depicting the optimal wealth expansion paths for, respectively, the healthiest 
and unhealthiest agents. Optimal consumption choices for the two types of agents are located at points $\mathrm{B}$ and $\mathrm{C}$, respectively. But point $\mathrm{C}$ is unattainable because it would involve going short on annuities, i.e. selling life-insured loans. But the moment an agent attempts to do so she reveals her health type which results in the borrowing rate being set at such a high level that borrowing is unattractive. It follows that there is a binding "self-imposed" borrowing constraint, the HBC is vertical at the endowment wage $w_{t}$, and all health types such that $\mu_{l} \leq \mu<\mu_{b c, t}$ are bunching at the endowment point A. ${ }^{6}$

For all agents featuring $\mu_{b c, t} \leq \mu \leq \mu_{h}$ the demand for annuities is positive and increasing in the survival probability. It thus follows from (30) that $\mu_{b c, t}<\bar{\mu}_{t}^{p}<\mu_{h}$, i.e. the relatively healthy agents obtain a better than actuarially fair rate of return on their private annuity holdings (because $\bar{\mu}_{t}^{p}<\mu_{h}$ ) whereas the comparatively unhealthy annuitants obtain a less than fair return $\left(\right.$ as $\left.\bar{\mu}_{t}^{p}>\mu_{b c, t}\right)$. The presence of unhealthy agents in the market allows the healthy to earn an informational rent.

Comparing the FI and AI cases we find that the informational asymmetry in the annuity market affects individuals via two related but distinct channels. First, whereas all agents are net purchasers of annuities $\left(A_{t}^{p}(\mu)>0\right.$ for $\left.\mu \in\left[\mu_{l}, \mu_{h}\right]\right)$ under symmetric information, the unhealthiest part of the population typically experiences a binding borrowing constraint and is thus absent from this market altogether $\left[A_{t}^{p}(\mu)=0\right.$ for $\left.\mu \in\left[\mu_{l}, \mu_{b c, t}\right)\right]$ when information is asymmetric. Second, the pooling rate under asymmetric information is "demographically unfair" in the sense that it is not based on the average demographic survival rate in the population of annuitants but on the asset-weighted survival rate $\bar{\mu}_{t}^{p}$. In order to demonstrate this phenomenon, note that the demographically fair pooling rate is defined as follows:

$$
1+\bar{r}_{t+1}^{f}=\frac{1+r_{t+1}}{\bar{\mu}_{t}^{f}},
$$

where the superscript $f$ stands for 'demographically fair' and $\bar{\mu}_{t}^{f}$ denotes the average survival rate of annuity purchasers among the cohort born in period $t$ :

$$
\bar{\mu}_{t}^{f} \equiv \frac{\int_{\mu_{b c, t}}^{\mu_{h}} \mu h(\mu) d \mu}{\int_{\mu_{b c, t}}^{\mu_{h}} h(\mu) d \mu} .
$$

Clearly, the demographically fair pooling rate is not sustainable in equilibrium because annuity firms would make a loss if they were to offer it to annuitants. To see why this is the case, note that the demand for annuities is increasing in the survival probability. It follows that $\bar{\mu}_{t}^{p}>\bar{\mu}_{t}^{f}$ and thus $1+\bar{r}_{t+1}^{p}<1+\bar{r}_{t+1}^{f}$ for all $t .^{7}$

6 See Heijdra and Reijnders (2009) and Villeneuve (2003) on this point.

7 Average annuity demand among participants in the market is given by:

$$
\bar{A}_{t}^{p} \equiv \frac{\int_{\mu_{b c, t}}^{\mu_{h}} A_{t}^{p}(\mu) h(\mu) d \mu}{\int_{\mu_{b c, t}}^{\mu_{h}} h(\mu) d \mu},
$$


The fundamental difference equation for the AI case is given by:

$$
k_{t+1}=\phi_{1}^{A I}\left(r_{t+1}, \bar{\mu}_{t}^{p}\right) w_{t}-\phi_{2}^{A I}\left(r_{t+1}, \bar{\mu}_{t}^{p}\right) \frac{\lambda \bar{\mu}_{t}^{p} w_{t+1}}{1+r_{t+1}}
$$

where $\phi_{1}^{A I}\left(r_{t+1}, \bar{\mu}_{t}^{p}\right)$ and $\phi_{2}^{A I}\left(r_{t+1}, \bar{\mu}_{t}^{p}\right)$ are defined as follows:

$$
\begin{aligned}
\phi_{1}^{A I}\left(r_{t+1}, \bar{\mu}_{t}^{p}\right) & \equiv \frac{1}{1+n+\lambda \bar{\mu}} \int_{\mu_{b c, t}}^{\mu_{h}}\left[1-\Phi\left(\mu,\left(1+r_{t+1}\right) / \bar{\mu}_{t}^{p}\right)\right] h(\mu) d \mu, \\
\phi_{2}^{A I}\left(r_{t+1}, \bar{\mu}_{t}^{p}\right) & \equiv \frac{1}{1+n+\lambda \bar{\mu}} \int_{\mu_{b c, t}}^{\mu_{h}} \Phi\left(\mu,\left(1+r_{t+1}\right) / \bar{\mu}_{t}^{p}\right) h(\mu) d \mu .
\end{aligned}
$$

The key features of the steady-state AI equilibrium are summarized in column (c) of Table 2. As far as the macroeconomic variables $\left(\hat{y}, \hat{k}, \hat{r}, \hat{w}, \hat{c}^{y}\right.$, and $\left.\hat{c}^{o}\right)$ are concerned the AI and FI equilibria are rather similar. In contrast, the composition of old-age consumption as well as expected lifetime utility differ dramatically for these two cases. The informational asymmetry in annuity markets leads to a redistribution from the unhealthy to the healthy agents in the economy. We elaborate on this point in Sect. 4 below.

Finally, Fig. 2 shows the steady-state health profiles for youth- and old-age consumption, annuity demand, and expected utility at birth - see the dash-dotted lines. Youth consumption is decreasing in health whilst the opposite holds for old-age consumption and the demand for annuities. Expected utility is U-shaped as was the case for the TY scenario.

\subsection{Transitional Dynamics}

We assume that the economy is initially in the steady state of the model without annuities. At a given time $t$ a private annuity market is introduced. The transition paths of the capital intensity and the expected lifetime utility of different health types are computed by means of an iterative procedure.

The results are given in Figs. 5 and 6 for both the full information (FI) equilibrium and the asymmetric information (AI) equilibrium in the private annuity market. The paths for the capital intensity are scaled by the steady-state equilibrium value in the

Footnote 7 continued and $\bar{\mu}_{t}^{p}-\bar{\mu}_{t}^{f}$ can be written as:

$$
\bar{\mu}_{t}^{p}-\bar{\mu}_{t}^{f}=\frac{\int_{\mu_{b c, t}}^{\mu_{h}}\left[A_{t}^{p}(\mu)-\bar{A}_{t}^{p}\right]\left[\mu-\bar{\mu}_{t}^{f}\right] h(\mu) d \mu}{\bar{A}_{t}^{p} \int_{\mu_{b c, t}}^{\mu_{h}} h(\mu) d \mu} \equiv \frac{\operatorname{cov}\left(A_{t}^{p}(\mu), \mu\right)}{\bar{A}_{t}^{p} \int_{\mu_{b c, t}}^{\mu_{h}} h(\mu) d \mu}>0,
$$

where $\operatorname{cov}\left(A_{t}^{p}(\mu), \mu\right)$ is the covariance between annuity demand and health (which is positive). 


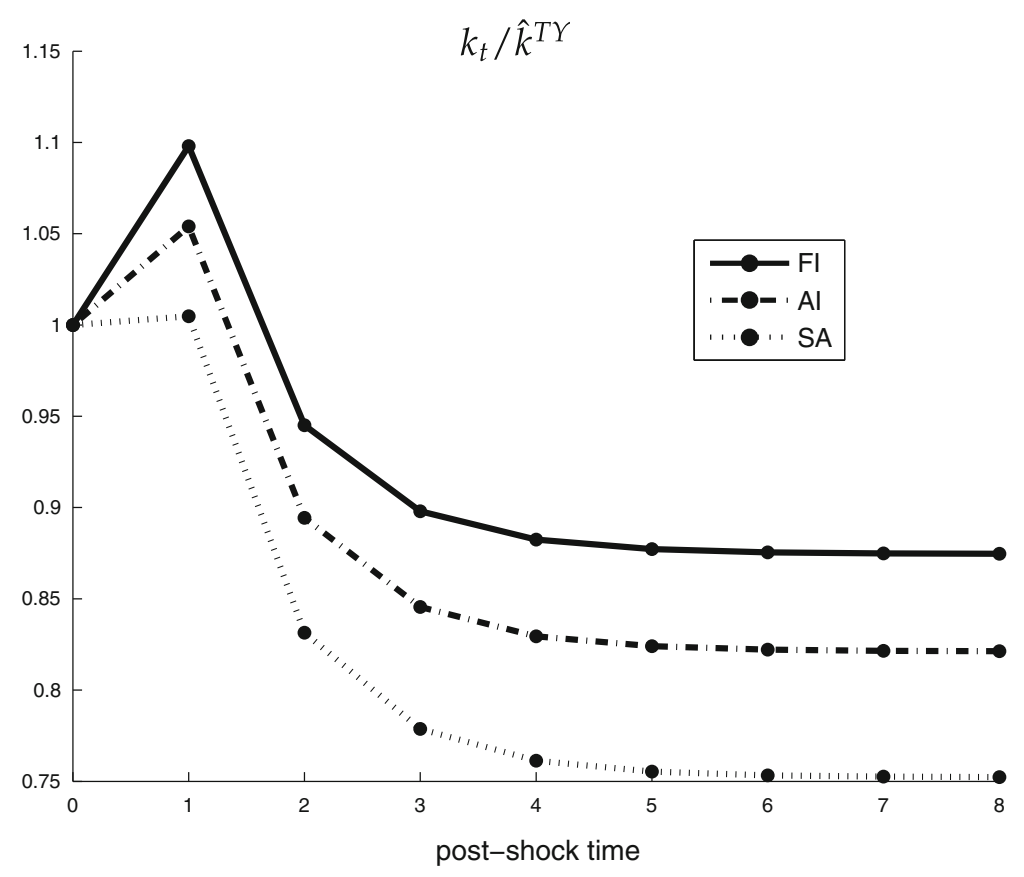

Fig. 5 Capital intensity relative to TY

no annuities case (TY). As such, a value in excess of unity indicates that the capital intensity increases relative to its benchmark scenario, when it falls short of unity there is a decrease. For lifetime utility we report the difference with the steady-state values obtained in the TY case, i.e. $\Delta \mathbb{E} \Lambda_{t}\left(\mu_{j}\right) \equiv \mathbb{E} \Lambda_{t}\left(\mu_{j}\right)-\mathbb{E} \hat{\Lambda}^{T Y}\left(\mu_{j}\right)$. Table 2 presents a numerical comparison between (unscaled) steady-state values.

We find that the introduction of a private annuity market boosts the capital intensity at first but gives rise to severe capital crowding out in the long run. The effects are more pronounced for the FI equilibrium than for the AI equilibrium. Agents save a larger part of their income in the first period and therefore consume less during youth and more in old age. Comparing the lifetime utility profiles we find that comparatively healthy agents prefer the AI to the FI equilibrium, and vice versa for the relatively unhealthy.

At the time the annuity market is opened up there are still accidental bequests in the economy which have been left by the previous generation. Hence, in the first period of the new regime young agents benefit from the higher return on their savings through full annuitization while also receiving the intergenerational transfer. Their expected utility level increases relative to the benchmark. However, from period $t+1$ (i.e. postshock time 1) onwards the transfers are abolished and all health types have a lower utility level under either equilibrium in the private annuity market than in the absence of annuities. This is an example of the so-called 'tragedy of annuitization', as described in Heijdra et al. (2010). Even though it is individually rational to fully annuitize (as the annuity rate of return exceeds the return on capital), this is not optimal from a social point of view. If all agents invests their financial wealth in the annuity market 
(a)

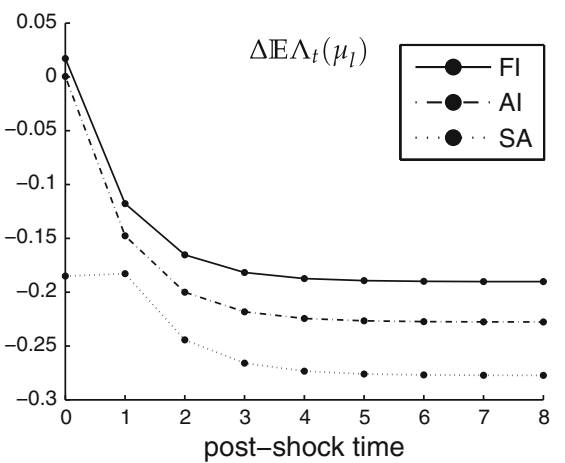

(c)

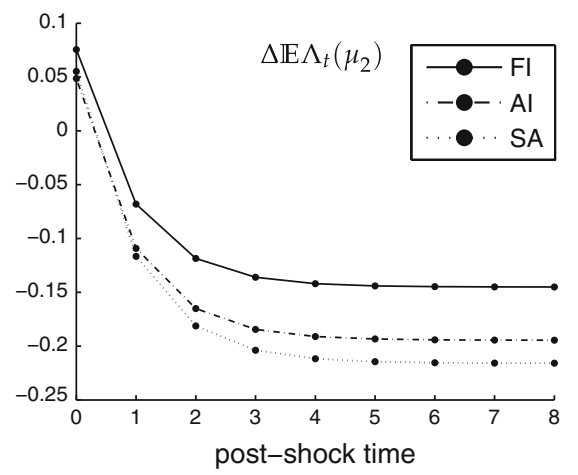

(e)

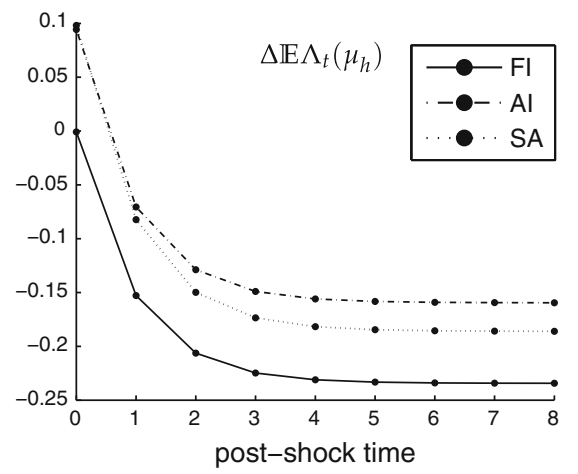

(b)

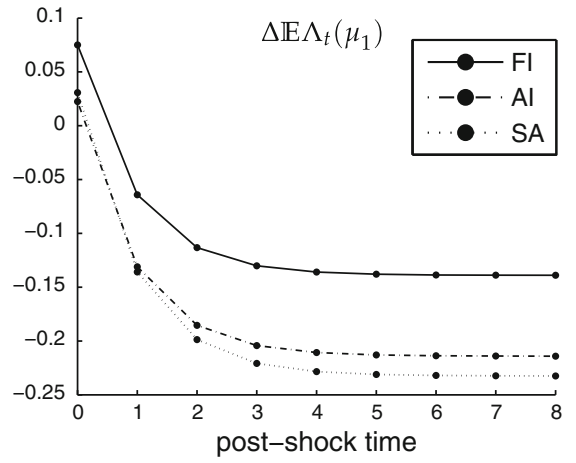

(d)

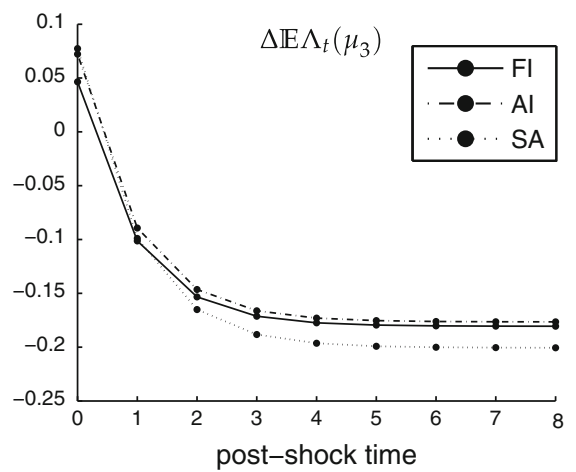

Fig. 6 Expected lifetime utility relative to TY. a Type $\mu_{l}: \Delta \mathbb{E} \Lambda_{t}\left(\mu_{l}\right)$, b type $\mu_{1}: \Delta \mathbb{E} \Lambda_{t}\left(\mu_{1}\right)$, $\mathbf{c}$ type $\mu_{2}$ : $\Delta \mathbb{E} \Lambda_{t}\left(\mu_{2}\right), \mathbf{d}$ type $\mu_{3}: \Delta \mathbb{E} \Lambda_{t}\left(\mu_{3}\right), \mathbf{e}$ type $\mu_{h}: \Delta \mathbb{E} \Lambda_{t}\left(\mu_{h}\right)$

then the resulting long-run equilibrium leaves future newborns worse off compared to the case where annuities are absent and accidental bequests are redistributed to the young. In other words, the introduction of an annuity market is welfare improving when considered in isolation, but not when the general equilibrium repercussions as a result of endogenous factor prices are taken into account. 
Table 3 Equivalent variations with private and social annuities

\begin{tabular}{lllll}
\hline & (a) AI & $\begin{array}{l}\text { (b) SA } \\
\theta=0.01\end{array}$ & $\begin{array}{l}\text { (c) SA } \\
\theta=0.02\end{array}$ & $\begin{array}{l}\text { (d) SA } \\
\theta=0.03\end{array}$ \\
\hline$\Pi\left(\mu_{l}\right)$ & 0.1540 & 0.1615 & 0.1700 & 0.1788 \\
$\pi\left(\mu_{l}\right)$ & 0.1835 & 0.1924 & 0.2025 & 0.2129 \\
$\Pi\left(\mu_{1}\right)$ & 0.1335 & 0.1376 & 0.1413 & 0.1441 \\
$\pi\left(\mu_{1}\right)$ & 0.1656 & 0.1707 & 0.1753 & 0.1788 \\
$\Pi\left(\mu_{2}\right)$ & 0.1117 & 0.1160 & 0.1201 & 0.1234 \\
$\pi\left(\mu_{2}\right)$ & 0.1464 & 0.1521 & 0.1573 & 0.1617 \\
$\Pi\left(\mu_{3}\right)$ & 0.0946 & 0.0992 & 0.1034 & 0.1071 \\
$\pi\left(\mu_{3}\right)$ & 0.1297 & 0.1360 & 0.1418 & 0.1468 \\
$\Pi\left(\mu_{h}\right)$ & 0.0804 & 0.0851 & 0.0896 & 0.0935 \\
$\pi\left(\mu_{h}\right)$ & 0.1147 & 0.1214 & 0.1277 & 0.1334 \\
\hline
\end{tabular}

As measures of utility are purely ordinal, the nominal difference in steady-state utility levels as presented in Table 2 cannot be easily interpreted. In order to evaluate the magnitude of utility differences in a more insightful way we use the metric of consumption-equivalent variations. That is, we determine how much additional consumption during youth one would have to give to an agent of a given health type in the private annuity market scenario in order to make her as well off as in the no-annuities case, keeping all prices (i.e. the wage rate and the interest rate) and old-age consumption fixed at their initial level. That is, we find that value of $\Pi(\mu)$ which satisfies the following equation:

$$
U\left(\hat{C}^{y}(\mu)+\Pi(\mu)\right)+\mu \beta U\left(\hat{C}^{o}(\mu)\right)=\mathbb{E} \hat{\Lambda}^{T Y}(\mu) .
$$

where $\mathbb{E} \hat{\Lambda}^{T Y}(\mu)$ is the steady-state benchmark utility level.

The results are given in column (a) of Table 3 . We present both unscaled and scaled values for the compensation measure, i.e. $\pi\left(\mu_{j}\right) \equiv \Pi\left(\mu_{j}\right) / \hat{C}^{y}\left(\mu_{j}\right)^{T Y}$ where $\hat{C}^{y}\left(\mu_{j}\right)^{T Y}$ is the steady-state youth consumption level of an agent with health type $\mu_{j}$ in the TY scenario. For example, to ensure that the unhealthiest type of agent has the same level of utility when there is a pooled private annuity market as when there are no annuities at all one would have to give her 0.1540 in terms of youth consumption. This corresponds to $18.35 \%$ of the consumption level she would have had in the absence of annuities. These numbers are quite significant, showing that the (negative) welfare effects of introducing a private annuity market in this economy are not inconsequential.

\section{Social Annuities}

Following Abel (1986) we now study the consequences of introducing mandatory social annuities. These can be interpreted, for example, as a fully funded pension system. Agents contribute a fixed amount $A_{t}^{S}$ during their youth and receive a benefit 
$\left(1+\bar{r}_{t+1}^{s}\right) A_{t}^{s}$ if they survive into the second phase of life, where $\bar{r}_{t+1}^{s}$ is the (implicit) net return on social annuities. All contributions are pooled and invested in the capital market. The gross return is then divided equally among the survivors. This implies that the following resource constraint should be satisfied:

$$
\left(1+r_{t+1}\right) L_{t} A_{t}^{s}=\left(1+\bar{r}_{t+1}^{s}\right) A_{t}^{s} \int_{\mu_{l}}^{\mu_{h}} \mu L_{t}(\mu) d \mu .
$$

Solving for the implied rate of return yields:

$$
1+\bar{r}_{t+1}^{s}=\frac{1+r_{t+1}}{\bar{\mu}}
$$

where $\bar{\mu} \equiv \int_{\mu_{l}}^{\mu_{h}} \mu h(\mu) d \mu$ is the average survival rate. Intuitively, as contributions are mandatory and independent of health type, the social annuity system is immune to adverse selection and forces everyone to participate. This makes the introduction of social annuities appear like an attractive option for the government: it can offer agents a higher rate of return on part of their savings than the private market can. Note that, in general, $\bar{r}_{t+1}^{s}>\bar{r}_{t+1}^{f}$, the demographically fair pooling rate as defined in (37), because all agents are forced to buy social annuities whereas not all agents purchase private annuities (if $\mu_{b c, t}>\mu_{l}$ it follows that $\bar{\mu}_{t}^{f}>\bar{\mu}$ ).

We assume that the agent can invest her remaining financial wealth in a pooled private annuity market. The lifetime budget constraint can be written as:

$$
C_{t}^{y}(\mu)+\frac{C_{t+1}^{o}(\mu)}{1+\bar{r}_{t+1}^{p}}=w_{t}+\frac{\lambda w_{t+1}}{1+\bar{r}_{t+1}^{p}}+\frac{\bar{\mu}_{t}^{p}-\bar{\mu}}{\bar{\mu}} A_{t}^{s} .
$$

Note that, ceteris paribus, the introduction of social annuities has a positive effect on the level of total human wealth as $\bar{\mu}_{t}^{p}>\bar{\mu}$ for all $t$ due to adverse selection in the private annuity market. By using (42) in combination with the Euler equation (32) we find that the agent's optimal plans are fully characterized by:

$$
\begin{aligned}
C_{t}^{y}(\mu)=\Phi\left(\mu,\left(1+r_{t+1}\right) / \bar{\mu}_{t}^{p}\right)\left[w_{t}+\frac{\lambda \bar{\mu}_{t}^{p} w_{t+1}}{1+r_{t+1}}+\frac{\bar{\mu}_{t}^{p}-\bar{\mu}}{\bar{\mu}} A_{t}^{s}\right], \\
A_{t}^{p}(\mu)+A_{t}^{s}=\left[1-\Phi\left(\mu,\left(1+r_{t+1}\right) / \bar{\mu}_{t}^{p}\right)\right] w_{t} \\
-\Phi\left(\mu,\left(1+r_{t+1}\right) / \bar{\mu}_{t}^{p}\right)\left[\frac{\lambda \bar{\mu}_{t}^{p} w_{t+1}}{1+r_{t+1}}+\frac{\bar{\mu}_{t}^{p}-\bar{\mu}}{\bar{\mu}} A_{t}^{s}\right], \\
\frac{\bar{\mu}_{t}^{p} C_{t+1}^{o}(\mu)}{1+r_{t+1}}=\left[1-\Phi\left(\mu,\left(1+r_{t+1}\right) / \bar{\mu}_{t}^{p}\right)\right]\left[w_{t}+\frac{\lambda \bar{\mu}_{t}^{p} w_{t+1}}{1+r_{t+1}}+\frac{\bar{\mu}_{t}^{p}-\bar{\mu}}{\bar{\mu}} A_{t}^{s}\right] .
\end{aligned}
$$

Compared to the model without social annuities discussed in Sect. 3.2 above there are a few noteworthy differences. Consumption during youth and old age are still 
proportional to human wealth, but the definition of human wealth has been augmented by a term reflecting the relative return on social annuities. From (44) we see that private annuity demand has been replaced by total annuity demand, the sum of private and social annuity holdings. As such, mandatory social annuities do indeed crowd out their private counterparts. Keeping everything else constant, this crowding out is more than one-for-one as the higher level of total income in the second period reduces the incentive for private saving.

We assume that the compulsory contribution to the social annuity system is proportional to wage income during youth, i.e. $A_{t}^{s}=\theta w_{t}$ with $0<\theta<1$. Note that for high values of $\theta$ agents might be overannuitized, i.e. they could be forced by the social security system to annuitize a larger portion of their financial wealth than they would voluntarily do. Since there is a borrowing constraint in the pooled annuity market this overannuitization cannot be undone by going short in private annuities. Figure 4 depicts a partial equilibrium representation of the effects of social annuities. In the presence of social annuities the endowment point shifts to point $\mathrm{D}$ and the relevant lifetime budget constraint is given by $\mathrm{HBC}_{S A}$. The thin dashed line connecting $\mathrm{A}$ and $\mathrm{D}$ is steeper than the downward sloping segments of $\mathrm{HBC}$ and $\mathrm{HBC}_{S A}$ because the rate on mandatory annuities is greater than the pooled private rate $\left(\bar{r}_{t+1}^{s}>\bar{r}_{t+1}^{p}\right)$. The choice set is enlarged for the healthier part of the population, but borrowing constraints become more severe for the unhealthier (as $\mu_{b c, t}^{S A}>\mu_{b c, t}$ ).

The fundamental difference equation for the SA case is given by:

$$
k_{t+1}=\phi_{1}^{A I}\left(r_{t+1}, \bar{\mu}_{t}^{p}\right) w_{t}-\phi_{1}^{S A}\left(r_{t+1}, \bar{\mu}_{t}^{p}\right) \theta w_{t}-\phi_{2}^{A I}\left(r_{t+1}, \bar{\mu}_{t}^{p}\right) \frac{\lambda \bar{\mu}_{t}^{p} w_{t+1}}{1+r_{t+1}},
$$

where $\phi_{1}^{A I}\left(r_{t+1}, \bar{\mu}_{t}^{p}\right)$ and $\phi_{2}^{A I}\left(r_{t+1}, \bar{\mu}_{t}^{p}\right)$ are defined directly below (38) and $\phi_{1}^{S A}\left(r_{t+1}, \bar{\mu}_{t}^{p}\right)$ is given by:

$$
\begin{aligned}
& \phi_{1}^{S A}\left(r_{t+1}, \bar{\mu}_{t}^{p}\right) \equiv \frac{1}{1+n+\lambda \bar{\mu}} \\
& \times\left[\frac{\bar{\mu}_{t}^{p}-\bar{\mu}}{\bar{\mu}} \int_{\mu_{b c, t}}^{\mu_{h}} \Phi\left(\mu,\left(1+r_{t+1}\right) / \bar{\mu}_{t}^{p}\right) h(\mu) d \mu-H\left(\mu_{b c, t}\right)\right] .
\end{aligned}
$$

The key features of the steady-state SA equilibria that emerge for different values of $\theta$ are summarized in columns $(\mathrm{d}-\mathrm{f})$ of Table 2 . The larger is the social annuity system (as measured by the magnitude of $\theta$ ), the stronger is capital crowding out and the larger is the proportion of borrowing-constrained (overannuitized) agents in the economy. We elaborate on this point in Sect. 4.1 below.

Finally, in Fig. 2 the steady-state health profiles for youth- and old-age consumption, private annuity demands, and expected utility at birth are illustrated - see the dotted lines. To avoid cluttering these figures, we restrict attention to the case of a 
"large" social annuity system with $\theta=0.03 .{ }^{8}$ Apart from the larger range of borrowing-constrained individuals, these profiles are very similar to the ones obtained for the AI case.

\subsection{Transitional Dynamics}

The transition paths of the capital intensity and lifetime utility after introducing both private and social annuities in the economy (denoted by SA) are given in Figs. 5 and 6 for the case that social security contributions amount to three percent of wage income $(\theta=0.03)$. We find that, compared to the benchmark of no annuities and transfers to the young, the capital intensity increases slightly for one period but afterwards decreases sharply. The overall effect on lifetime utility is negative for all health types, except for the impact period in which the transfers have not yet been abolished.

In order to evaluate the magnitude of the relative welfare decrease in the steady state we calculate the consumption-equivalent variations for three different values of $\theta$, see columns (b-d) in Table 3 and Sect. 3.3 above. Recall that column (a) (featuring $\theta=0$ ) corresponds to the pooling equilibrium. We find that the equivalent variations increase monotonically in $\theta$ for all health types, implying that the equilibrium becomes progressively worse in welfare terms when the contribution to the social annuity system increases. At first view this might seem somewhat counterintuitive, as social annuities offer agents a higher rate of return on a fixed part of their savings than private annuities do, keeping everything else constant. However, it is exactly this ceteris paribus condition which is misleading.

Importantly, the introduction of social annuities has two opposing effects on the rate of return on private annuities. First of all, there is a partial equilibrium effect. The mandatory investment in social annuities results in a decrease in the demand for private annuities. Unhealthy agents reduce their private annuity demand disproportionally more than healthy agents do. As a consequence, the asset share of healthy agents increases and thereby the degree of adverse selection in the private annuity market. This leads to a decrease in the rate of return on private annuities, in line with the findings of by Abel (1986), Walliser (2000), and Palmon and Spivak (2007).

However, there is also a general equilibrium effect which partly offsets the decrease. The total level of savings decreases in the steady state, leading to a rise in the rental rate of capital relative to the scenario without social annuities. This response is not taken into consideration when the focus is restricted to partial equilibrium analysis or when the interest rate is assumed to be exogenously fixed.

The net effect on the private annuity rate is negative in all our simulations. Overall, we find that in the long run the negative effects of introducing social annuities (a lower wage rate and a lower return on private annuities) outweigh the positive effect (a demographically fair rate of return on a part of financial wealth) as is evident from the drop in welfare of future generations.

\footnotetext{
8 Although this contribution rate does not represent a large proportion of wage income during youth, the social annuity system is nevertheless large in terms of the private annuity demands expressed by the unhealthiest agents in the AI equilibrium.
} 


\section{Conclusion}

In this paper we have constructed a discrete-time general equilibrium model featuring exogenous growth and overlapping generations of heterogeneous agents who are distinguished by their health status. An agent's health type is assumed to be private information. We show that if a private annuity market is introduced in this economy then it will be characterized by a pooling equilibrium. Due to adverse selection, the resulting annuity rate of return is less than the actuarially fair pooling rate. Even though it is individually optimal to invest in annuities, agents of all health types are in the long run worse off in welfare terms compared to the case where annuities are absent and accidental bequests are redistributed to the young.

We have also studied the welfare implications of a social security system with fixed mandatory contributions for all health types. These social annuities are immune to adverse selection and therefore offer a higher rate of return than private annuities do under asymmetric information. However, they have a negative effect on steady-state welfare. The positive effect of a higher rate of return on a fixed part of savings and a higher return on capital in equilibrium is outweighed by the negative consequences of increased adverse selection in the private annuity market and a lower wage rate.

Our results suggest that privatization of social security may be welfare improving when annuity markets are characterized by asymmetric information. Elimination of social annuities reduces the degree of adverse selection in the private annuity market, increases the level of savings, and has a positive effect on lifetime utility for all health groups in the population. In general, lifetime utility of newborns is highest in the complete absence of annuities provided the redistribution scheme transfers accidental bequests to the newly arrived young agents.

Open Access This article is distributed under the terms of the Creative Commons Attribution License which permits any use, distribution, and reproduction in any medium, provided the original author(s) and the source are credited.

\section{References}

Abel, A. B. (1986). Capital accumulation and uncertain lifetimes with adverse selection. Econometrica, 54, 1079-1098.

Cannon, E., \& Tonks, I. (2008). Annuity markets. Oxford: Oxford University Press.

Heijdra, B. J. \& Mierau, J. O. (2012). The individual life-cycle, annuity market imperfections and economic growth. Journal of Economic Dynamics and Control (forthcoming).

Heijdra, B. J., Mierau, J. O., \& Reijnders, L.S.M. (2010). The tragedy of annuitization. Working paper 3141, München: CESifo.

Heijdra, B. J. \& Reijnders, L.S.M. (2009). Economic growth and longevity risk with adverse selection. Working paper 2898, München: CESifo.

Palmon, O., \& Spivak, A. (2007). Adverse selection and the market for annuities. Geneva Risk and Insurance Review, 32, 37-59.

Pauly, M. V. (1974). Overinsurance and public provision of insurance: The role of moral hazard and adverse selection. Quarterly Journal of Economics, 88, 44-62.

Pecchenino, R. A., \& Pollard, P. S. (1997). The effects of annuities, bequests, and aging in an overlapping generations model with endogenous growth. Economic Journal, 107, 26-46.

Rothschild, M., \& Stiglitz, J. (1976). Equilibrium in competitive insurance markets: An essay on the economics of imperfect information. Quarterly Journal of Economics, 90, 629-649. 
Sheshinski, E. (2008). The economic theory of annuities. Princeton: Princeton, N.J.: University press.

Villeneuve, B. (2003). Mandatory pensions and the intensity of adverse selection in life insurance markets. Journal of Risk and Insurance, 70, 527-548.

Walliser, J. (2000). Adverse selection in the annuities market and the impact of privatizing social security. Scandinavian Journal of Economics, 102, 373-393.

Yaari, M. E. (1965). Uncertain lifetime, life insurance, and the theory of the consumer. Review of Economic Studies, 32, 137-150. 